\title{
Squamous Papilloma of the External Auditory Canal
}

\author{
Sung Il Cho ${ }^{\mathrm{a}, \mathrm{b}}$
}

\begin{abstract}
A 24-year-old man presented with a papillomatous lesion within the right ear canal and adjoining conchal skin. Histopathologic examination of the excised mass revealed features of squamous papilloma. The site of origin was quite unusual, despite its frequent occurrence in the head and neck such as nose, pharynx, larynx, tracheobronchial tree. We present a case of squamous papilloma presenting as aural lesion with a review of the literature.
\end{abstract}

Keywords: Papilloma; Ear canal; Aural lesion

\section{Introduction}

Squamous papilloma has been reported occurring in the upper and lower respiratory tract such as the nose, pharynx, larynx, tracheobronchial tree. However, aural papilloma as a single entity has been rarely reported [1]. When they occur on the external auditory canal (EAC), they are most benign and asymptomatic. Here we present the case of a squamous papilloma of the EAC.

\section{Case Report}

A 24-year-old man had a 1-month history of right ear pruritus. He denied hearing loss, otalgia, vertigo, tinnitus, and

Manuscript accepted for publication April 25, 2013

${ }^{\mathrm{a}}$ Department of Otolayngology-Head and Neck Surgery, Chosun University School of Medicine, Gwangju, South Korea

${ }^{\mathrm{b} C o r r e s p o n d i n g ~ a d d r e s s: ~ D e p a r t m e n t ~ o f ~ O t o l a r y n g o l o g y-H e a d ~ a n d ~}$ Neck Surgery, Chosun University Hospital, 365 Pilmun-daero, Dong-gu, Gwangju 501-717, South Korea. Email: chosi@chosun.ac.kr

doi: http://dx.doi.org/10.4021/jmc1260w disequilibrium. He had no history of any papilloma or other medical problems. Physical examination revealed a papillomatous lesion within the right ear canal and adjoining conchal skin (Fig. 1). The tympanic membrane was normal. Facial nerve function and neurologic examination findings were normal. There was no evidence of such lesion anywhere else in the body including the respiratory tract and genitalia. The patient underwent a surgical excision under local anesthesia. The lesion was found not to involve cartilage of the ear canal. Histopathology confirmed the diagnosis of squamous papilloma (Fig. 2). Complete healing was achieved after 2 weeks. During follow-up of 12 months, no recurrence was found.

\section{Discussion}

Squamous papillomas are caused by the human papilloma virus (HPV), a DNA virus of the Papovaviridae family [2]. Aural papillomas are generally associated with HPV types 6 and 11. Clinical presentations of HPV infection are various; common warts, vulvar or oral papilloma, epidermodysplasia verruciformis, keratoacanthoma, etc [3]. Squamous papil-

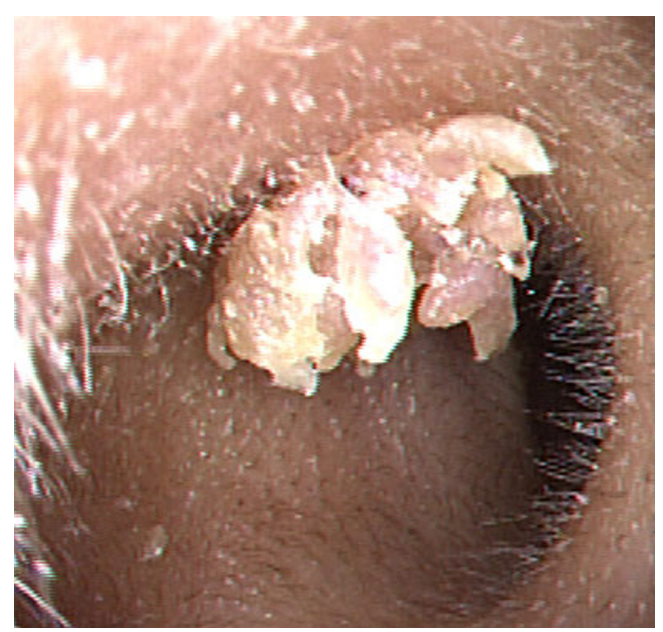

Figure 1. A papillomatous lesion in the right external auditory canal. Note finger-like projections at the surface. 


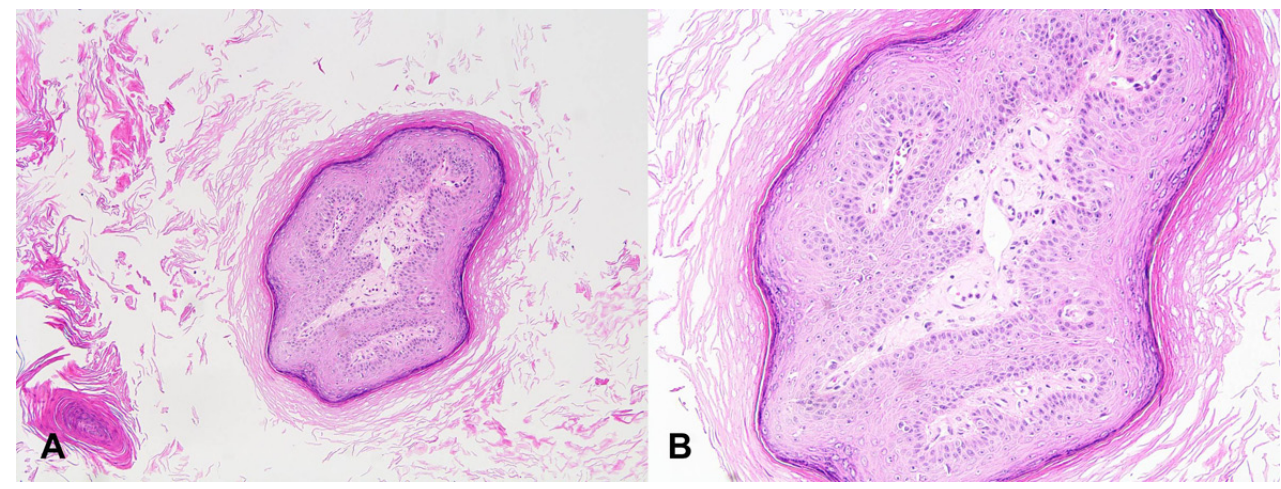

Figure 2. (A) Marked hyperkeratosis with fibrovascular stroma. $(H \& E, \times 100)(B)$ No dysplasia is seen at high power magnification $(H \& E, \times 200)$.

lomas typically present as single pedunculated masses with numerous finger-like projections at the surface [4]. There are no association with age or sex [2]. Upper aerodigestive tract is the most common affected sites in the head and neck region. However, there have been no reports of transmission from lesions arising in the aerodigestive tract to the EAC. It probably transmitted from contaminated fingers or objects rather than through sexual contact or vaginal delivery [2]. Papillomas may arise from any site in the EAC, in either the bony or the cartilaginous portions [5]. Although rare, malignant change of these lesions in the EAC has been reported. HPV subtypes 16 and 18, the presence of chronic otitis media are associated with an increase chance of malignancy [6]. For this reason, all lesions have to be differentiated from carcinoma hence biopsy is mandatory [7]. The treatment of squamous papilloma is mainly surgical. It is necessary to perform complete resection of the lesion to prevent recurrent disease. Removal of the papilloma may be undertaken in one of several ways include cryosurgery, electrodissection, electrodissection plus curettage, and carbon dioxide laser resection. Significant scarring and subsequent stenosis could happen after treatment of large papillomas in the EAC. Antibiotic-impregnated gauze or silastic tube may be used as stent after treatment to reduce the chance of stenosis $[1,7]$.

\section{References}

1. Yadav SP, Chanda R, Goyal N, Chanda S. Aural papillomatosis in a 3-year-old child. Int J Pediatr Otorhinolaryngol. 2002;66(2):185-187.

2. Abboud O, Saliba I. Ear canal papillomas. QJM. 2012;105(7):707-708.

3. Habif TP. Warts, herpes simplex, and other viral infections. In: Habif TP, editor. Clinical Dermatology, 5th edn. Elsevier: Health Science Division; 2010. p. 454-90.

4. Goodstein LA, Khan A, Pinczewski J, Young VN. Symptomatic squamous papilloma of the uvula: report of a case and review of the literature. Case Rep Otolaryngol. 2012;2012:329289.

5. Myer CM, 3rd, Woodruff SM. Pathologic quiz case 2. Squamous papilloma of the external auditory canal. Arch Otolaryngol. 1983;109(3):200-201, 203.

6. Miah MS, Crawford M, White SJ, Hussain SS. Malignant transformation from benign papillomatosis of the external auditory canal. Otol Neurotol. 2012;33(4):643647.

7. Blair RL, Irani BS, Low C. Aural papillomatosis--treatment with the carbon dioxide laser. J Laryngol Otol. 1998;112(6):565-566. 